\title{
Technology Acceptance in Crowdfunding Among Retailers
}

\author{
MOHAMMED HARIRI BAKRI ${ }^{1}$, MOHAMMED SOLEH MD RADZAI ${ }^{2}$, \\ AHMAD MUJAHID MAT RASID 3 \\ 1,2,3Faculty of Technology Management and Technopreneurship, UNIVERSITI TEKNIKAL MALAYSIA MELAKA,

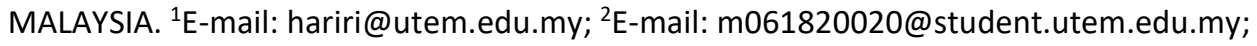 \\ ${ }^{3}$ E-mail: a.mujahyd@gmail.com
}

\begin{abstract}
Crowdfunding is currently Malaysia's fastest growing source of alternative finance for companies. It is an enticing opportunity for entrepreneurs with innovative ideas who would not otherwise have found capital to leverage the power of the audience to bring goods and projects from the ground. Crowdfunding has traditionally been the go-to funding solution for individuals, startups and entrepreneurs. But more recently, retailers and larger companies have been using crowdfunding as an investment route, market research tool or promotional technique. The obvious attraction of crowdfunding for retailers is that it sidesteps the need to convince a bank or investor you can make their investment worthwhile. But the rewards of the crowdfunding model are not just financial. A crowdfunding campaign can raise awareness of a brand or product, deliver valuable information about demand for a product or service, and create an already established customer base once a campaign is complete. Hence, this research focused on determining the factors that could influence the prospective retailers' intention to collect fund from crowdfunding platform. The research selected the UTAUT model to determine the prospective retailer's intention toward collecting fund to the crowdfunding project. There were four independent variables, namely performance expectancy, effort expectancy, social influence, and reliability. The intention of the prospective retailer was selected as the dependent variable. With respect to the literature review, four hypotheses were developed in this study. To test the developed hypothesis in this study, descriptive research was adopted by applying a self-administered questionnaire distributed to respondents. For this study, convenience sampling was selected, whereby 379 respondents responded and answered the questions. All the independent variables have shown that they were positively significant to the intention of the prospective retailer. Hence, the intention of prospective retailer is influenced by performance expectancy, effort expectancy, social influence, and reliability. This research successfully contributed to the knowledge in this field by applying the UTAUT factor in the context of crowdfunding for expanding retail business. Regarding practitioners in this field, this research could act as a guideline or reference to enhance the retailer's intention to collect fund in a crowdfunding project. Lastly, for policymakers, it is hoped that this research could be used as a standard and reference for future crowdfunding initiatives by the government.
\end{abstract}

Keywords: Crowdfunding, technology, retailers, UTAUT, capital

JEL Classification: C1, L2 


\section{Introduction.}

Nowadays crowdfunding is becoming fairly important among the public, business and government services. This offers an opportunity to quickly and effectively gather financial capital. Crowdfunding initiators call for the funding of specific projects and initiatives, while participants (also termed backers or sponsors) make contributions either by donating or in exchange for a reward. Such an approach to fundraising is typically available to the crowd and applied over the internet. Crowdfunding was used for several different purposes. The several primary types are reward-based, equity-based, lendingbased, and donation-based. The growth of online crowdfunding markets has been regarded as a strategy in many countries as part of the internet economy, and the scale of the world's crowdfunding markets is projected to reach $\$ 90$ billion by 2020 .

According to (Securities Commission Malaysia, 2019), the Government of Malaysia approved the structure for equity crowdfunding (ECF) in an attempt to obtain financial opportunities in 2015. This initiative has placed Malaysia as the first country to implement ECF legislation in the Asia-Pacific region. Six equity crowdfunding operators from which entrepreneurs and small businesses can seek assistance in growing their business and capital markets for growth have been announced by the Malaysian government(Rahim, $\mathrm{N}$ et al 2019). SMEs are important to our economy because they make up 97 percent of Malaysia's business establishments; they contribute 37 percent of the Gross Domestic Product (GDP) of the country and 65 percent of the employees of the country. The government is planning to drive the contribution of SMEs to GDP to 41 percent by 2020. (Securities Commission Malaysia, 2019) stated that eight new Recognized Market Operators comprising three equity ECF and five peer-to-peer (P2P) funding platforms were announced by the Security Commission in 2019. The ECF and P2P financing provides Micro, Small and Medium Enterprises (MSMEs) with an alternative source of capital to support business growth, finance working capital and meet another financial necessity(Ismail,S. et al 2017). Almost RM350 millions of alternative financing for almost 900 Malaysian MSMEs has been supported by the ECF and P2P funding markets(Bakri et al 2017).

The building blocks of a large economy are small or medium-sized enterprises and startups, as well as the self-employed and micro enterprises. They are likely to find it difficult to obtain adequate loans from banks, institutional investors, or governments, considering their size and other potential factors (Terpstra and Olson, 1993, Mohd Noor et al 2020). However, the advent of crowdfunding has provided an easy but efficient funding mechanism for economic organizations at such levels (Mohd Noor et al 2020).

As the number of small business failures is rising, many scientists are concentrating their efforts on finding the reasons behind these failures. While most of the research was conducted in western countries (Fredland and Morris, 1976), (Dipietro and Sawhney, 1977), and (Peterson, Kozmetsky and Ridgway, 1983), no serious attempt has ever been made to determine causes for small business failure in Malaysia. The study noted that financial difficulties, labour shortages, lack of technological adoption, high turnover and the challenge of expanding the market are the key obstacles to SME development (Hu, 2017). The growth of SMEs is hindered by these hiccups and, to date, there has been no concrete plan proposed by the government to solve these problems (Hu, 2017). Consequently, the industry did not expand as rapidly as expected.

In terms of perception, finance was seen by many small businesses in Malaysia as the greatest challenge in running a business (Faique et al,2017) . Many innovative projects have failed in collecting enough funds, which poses a great challenge and casts a shadow over the crowdfunding industry. Crowdfunding platforms could not function as expected because of technical problems or wrong manipulation. Retailers face difficulty in securing funds because of poor record keeping and insufficient documentation. The system for applying for research funding has been sluggish in the past, sometimes slowing down the process of marketing promising technologies, and this traditional source of funding does not help the production of prototyping and product formation. Today, the crowdfunding movement spreads to the far reaches of the world's cultures because of the explosion of vibrant social networking sites(Bakri et al, 2018). Crowdfunding helps to bridge the gap in business and practice 
between concepts and fact. The purpose of this study to determine the factors influence prospective retailers' intentions to participate in crowdfunding projects.

\section{Literature Review.}

According to (Burtch, Ghose and Wattal, 2012), the Internet-based crowdfunding platforms facilitate all crowdfunding transactions, and also offer an efficient option for all transfers of funds. Another researcher (Voorbraak, 2011) also defines that in exchange for a monetary or non-monetary return on investment, crowdfunding is the process of one person seeking and accepting money and other resources from several people to finance a product or project(Ali et al, 2013). The researcher found out that the study of both researcher (Burtch, Ghose and Wattal, 2012) and (Voorbraak, 2011) show that the community or duties must be successful in pursuing the crowdfunding effort. This also supports the research of (Burkett, 2011), which comments that in any crowdfunding campaign, there are three tasks to be fulfilled. From Burkett's research, there is an intermediary between fundraisers and investors who functions as a matchmaker.

The key function of the intermediary is also regarded as a platform for crowdfunding. Then, fundraisers raising the fund via the crowdfunding platforms. Finally, there are investors, it is described as the 'crowd' from the crowdfunding term, crowd is a group of individuals who help the fundraiser business financially, bearing the risk together and expecting a certain payoff(Rahman A et al ,2016). The researcher agrees with the research findings of Burkett.

Malaysia is beginning to acknowledge the value of crowdfunding, which can be seen by the government's and some private agencies' concerted efforts to bring it to the ecosystem of local funding (Asian Institute of Finance, 2014). In Malaysia, there are three major Web-based crowdfunding platforms, namely, pitchIN, Mystartr and Malaysia Digital Economy Corporation (MDEC) (Asian Institute of Finance, 2014). However, (Asian Institute of Finance, 2017) stated these Crowdfunding Platform (CFPs) are intended for crowdfunding based on rewards and donations. So far, just 19 out of 103 ventures had successfully raised funding via these platforms as of August 2015.

In fact, all of the successful projects focused on community projects, film, video, music, and arts. In Malaysia, the market volume of CFPs was over US\$ 5 million between 2013 and 2015. This accounted for roughly 6 percent of overall business activity across Southeast Asia. Donation-based crowdfunding, which accounted for 92.4 percent of the overall Malaysian market, which raised a total of US\$ 4.68 million, dominated the total volume. A total of 6 percent was accrued through reward-based crowdfunding, which amounted to over US\$325,000 during the time. In addition to existing CFPs in Malaysia, recently, in June 2015, the Malaysian Securities Commission approved six equity-based CFPs for operation by the end of December 2015(Ali et al,2015,Bakri et al 2015). Malaysia was one of the first to offer regulatory approval for equity crowdfunding in Southeast Asia. Alix Global, ATA Plus, Crowdonomic, Eureeca, pitchIN, and CrowdPlus.asia are among the authorized equity-based CFPs in Malaysia.

\section{Theoretical Framework of The Study.}

In order to predict the intent of users of a particular technology, several researchers have suggested several models of technology acceptance. It is of very important importance to measure both user experience and satisfaction of several new technological tools, especially at the recent shutdown of the Google Glass project (Shin and Hwang, 2017). This important challenge inspired numerous researchers to suggest several technology adoptions models for future users. In fact, hypothesis and models of purpose to use technologies have been suggested and tested by (Ajzen and Fishbein, 1977) and (Davis, 1989).

\subsection{UTAUT Model.}

(Venkatesh et al., 2003) integrated eight models and theories that relate to technology acceptance, such as technology acceptance model (TAM), theory of reasoned action (TRA), innovation diffusion 
theory (IDT), and the theory of planned behavior (TPB) by proposing the UTAUT model to address these limitations. There are a number of key factors which influenced the behavioral intention of an individual which are: performance expectancy, effort expectancy, social influence, and facilitating conditions. (Venkatesh et al., 2003) also added that the model is moderated by gender, experience, age, and voluntariness of use. A study on the consumer reception of new media and new IT has been widely used in the UTAUT model. Therefore, this research intends to examine acceptance of technology in crowdfunding among retailers in Melaka by applying the UTAUT model.

The establishment of the UTAUT model has allowed leaders, managers, and owners of general businesses to assess the load of new technology, describe the explanations in terms of figures for accepting technology in their business organization, and predict users' behavior (Huang and Kao, 2015). About $70 \%$ of the variance in behavioral intentions to use technology, and about $50 \%$ of the variance in technology use can be explained by UTAUT (Straub, 2009). UTAUT has four key constructs, which are performance expectancy, effort expectancy, social influence, and facilitating conditions.

\subsection{UTAUT Constructs.}

\subsubsection{Performance Expectancy.}

According to (Venkatesh et al., 2003) the degree of progress in performance upon which individual believe to notice as a consequence of use of detailed new information or technology refers to performance expectancy (Bakri et al 2016). In the context of this research, the range to which the encounters faced by local communities are expected to be resolved through the crowdfunding project is applied as the definition of PE.

\subsubsection{Effort Expectancy.}

The perceived extent of convenience presented using some new information or technology refers to effort expectancy (EE) as per (Venkatesh et al., 2003). Moreover, it is defined as 'the degree of ease associated with use of the system', which means the system or technology is easy to use, learn, understand, and leading to less individual effort. In this study, EE defined as the easiness through crowdfunding which investors assume participating in retailer funding.

\subsubsection{Social Influence.}

Social influence (SI) is the amount to which the consumer has confidence in that significant people advocate the use of new information technology by individuals (Al-Lamy et al 2018). Like the concept of subjective norm, this concept refers to the level of impact that significant people have on a person's behavior. In this study, the definition of SI described as 'the degree to which an individual perceives that important others believe he or she should use the new system'. Hence, this is understood as whether one is affected by another in the decision of using a new system or technology

\subsubsection{Reliability.}

Reliability (public confidence and ethics) and expertise (knowledge and competency) refer with perceived trust to the user's subjective degree of belief in the of a crowdfunding platform, and points to a platform's capacity for monitoring and post-management (Moon and Hwang, 2018).

\subsubsection{Research Framework.}

In order to predict the willingness to use crowdfunding platforms by retailers in Melaka, this research has developed a framework from the constructs of UTAUT model and the addition of reliability. The four constructs of UTAUT model are PE, EE, SI, and reliability was added in this research as illustrated in Figure 1. 
Figure 1. Research Model

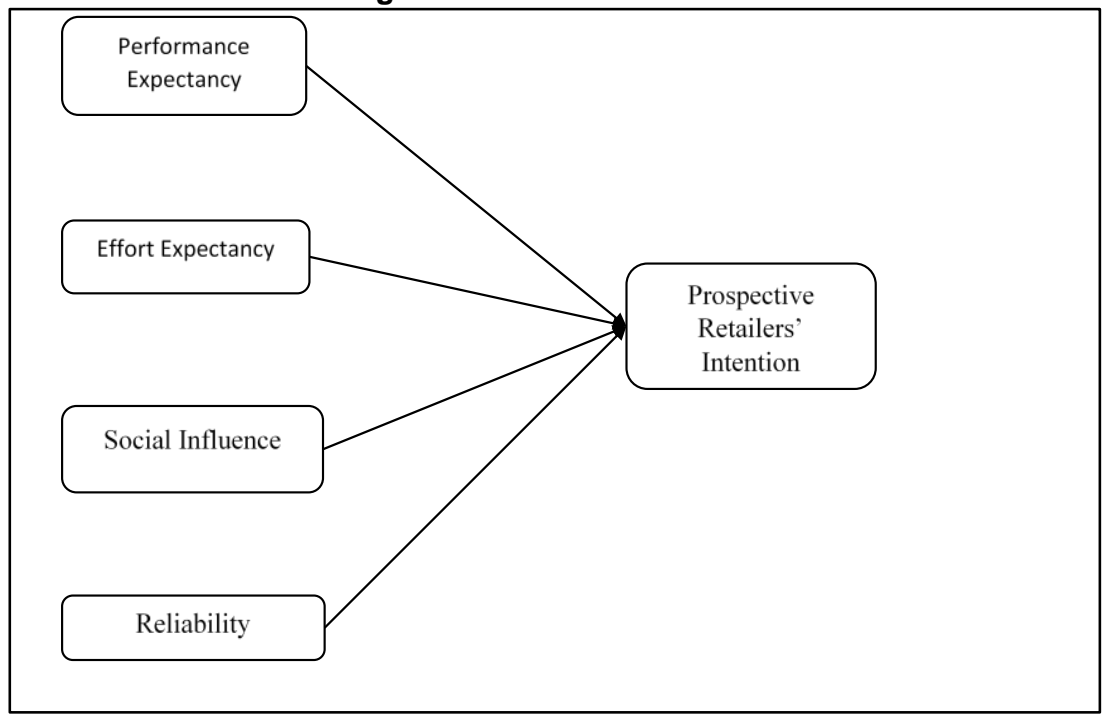

\subsection{Reliability.}

As for REL, the descriptive analysis is displayed in Table 1. Here, the results of the mean value show that it ranges from 3.97 to 4.02 . The value of means could be interpreted that most of the respondents agreed with the statements in the items.

Table 1. Descriptive Analysis for Reliability

\begin{tabular}{|c|c|c|}
\hline Items & Mean & Std Deviation \\
\hline $\begin{array}{c}\text { REL1 - "I think the manager of appropriate technology-related } \\
\text { crowdfunding platform will monitor and supervise well whether the } \\
\text { proponents have been working as originally planned." }\end{array}$ & 3.99 & 0.680 \\
\hline $\begin{array}{c}\text { REL2 - "I think that the manager of appropriate technology related } \\
\text { crowdfunding platform has well evaluated the competence and } \\
\text { reliability of proposers in advance." }\end{array}$ & 3.97 & 0.646 \\
\hline $\begin{array}{c}\text { REL3 - "I think the manager of appropriate technology related } \\
\text { crowdfunding platform will do well post-management, including } \\
\text { feedback, even after the proposed technology project is complete." }\end{array}$ & 4.02 & 0.684 \\
\hline
\end{tabular}

\subsection{Reliability Analysis Result.}

The main reason for testing reliability is to measure the scale's internal consistency (Pallant, 2011). This refers to the degree of each item in the construct that sticks together. The most frequently used method to check reliability is Cronbach's Alpha coefficient. According to (Pallant, 2011), Cronbach's Alpha coefficient is ideally accepted for a scale of more than 0.7 . Hence, all the reliability values in this study were more than 0.7 , which is above the acceptable standard. The Cronbach's Alpha for all components is displayed in Table 2.

\subsection{The Relationship between Independent Variables and Dependent Variable.}

\subsubsection{Correlation Analysis.}

Correlation analysis is used to describe the strength and route of a linear relationship that exists between two variables, which are the dependent and independent variables (Pallant, 2011). In this study, the correlation analysis explored the relationship of each independent variable, which were PE, $\mathrm{EE}, \mathrm{SI}$, and REL, and the dependent variable, which was the prospective retailer's intention to involve in the crowdfunding project. 
Table 2. Reliability Result

\begin{tabular}{|c|c|c|}
\hline Variable & Cronbach's Alpha & $\begin{array}{c}\text { Number of } \\
\text { Items }\end{array}$ \\
\hline Performance expectancy & 0.957 & 4 \\
\hline Effort expectancy & 0.895 & 3 \\
\hline Social influence & 0.866 & 4 \\
\hline Reliability & 0.918 & 4 \\
\hline
\end{tabular}

From the results, respondent with low score PE will associated with low intention to use e-payment $\left(x^{2}=67.681 ; p<0.001\right)$. This result indicates there have strongly positive significant relationship between performance expectancy and intention retailer to use crowdfunding platform. Furthermore, variable REL indicates in high score which is $89.9 \%$, and had positive relationship with prospective retailers' intention $\left(x^{2}=71.924 ; p<0.001\right)$. Respondent with high score social influence with high intention to use e-payment $\left(x^{2}=175.536 ; p<0.001\right)$.

Since the data was abnormal distribution, the relationship between independent variable and dependent variable will be present in chi-square correlation as shown in Table 3. Chi-square correlation will determine relationship between two categorical variables.

Table 3. Chi-square Correlation

\begin{tabular}{|c|c|c|c|c|}
\hline Variable & $\begin{array}{c}\text { Low PRI } \\
\text { n (\%) }\end{array}$ & $\begin{array}{c}\text { High PRI } \\
\text { n (\%) }\end{array}$ & $x^{2}$ & $\begin{array}{c}\text { p-value } \\
\text { (2-sided) }\end{array}$ \\
\hline Performance Expecta & & & \multirow{3}{*}{$\begin{array}{c}67.68 \\
1\end{array}$} & \multirow{3}{*}{$\underset{* *}{0.000}$} \\
\hline Low Score & $127(73.8 \%)$ & $65(31.4 \%)$ & & \\
\hline High Score & $45(26.2 \%)$ & $142(68.6 \%)$ & & \\
\hline Effort Expectancy & & & \multirow{3}{*}{$\begin{array}{c}68.04 \\
2\end{array}$} & \multirow{3}{*}{$\underset{* *}{0.000}$} \\
\hline Low Score & $132(76.7 \%)$ & $71(34.3 \%)$ & & \\
\hline High Score & $40(23.3 \%)$ & $136(65.7 \%)$ & & \\
\hline Social Influence & & & \multirow{3}{*}{$\begin{array}{c}175.5 \\
36\end{array}$} & \multirow{3}{*}{$\underset{* *}{0.000}$} \\
\hline Low Score & $154(89.5 \%)$ & $44(21.3 \%)$ & & \\
\hline High Score & $18(10.5 \%)$ & $163(78.7 \%)$ & & \\
\hline Reliability (RE & & & \multirow{3}{*}{$\begin{array}{c}71.92 \\
4\end{array}$} & \multirow{3}{*}{$\underset{* *}{0.000}$} \\
\hline Low Score & $85(49.4 \%)$ & $21(10.1 \%)$ & & \\
\hline High Score & $87(50.6 \%)$ & $186(89.9 \%)$ & & \\
\hline
\end{tabular}

Independent variables that contribute to Low intention to perceived retailer intention is PE, EE, and SI. While Independent variables that contribute to High intention to Prospective retailers' intention is REL. $(P<0.001)$

\subsubsection{Logistic Regression Analysis.}

All variable with $p<0.25$ in sample logistic regression were included in the multiple logistic regression. Multiple binary logistic regression Enter method was used to determine the contributing factors towards retailers' intention. The data fit the final model well because the significant value for Omnibus Tests of Model Coefficients was less than $0.05(p=0.000)$. It was supported by Hosmer and Lemeshow Test (Table 4), as the significant value of this test was more than $0.05(p=0.254)$.

Table 4. Reliability Test

\begin{tabular}{|l|l|l|}
\hline \multicolumn{1}{|c|}{ Hypothesis } & Accepted & Not Accepted \\
\hline $\begin{array}{l}\text { H1: Performance expectancy has a positive effect on } \\
\text { prospective retailers' intention to participate in crowdfunding } \\
\text { projects. }\end{array}$ & $\sqrt{ }$ \\
\hline $\begin{array}{l}\text { H2: Effort expectancy has a negative effect on prospective } \\
\text { retailers' intention to participate in crowdfunding projects }\end{array}$ & & \\
\hline
\end{tabular}




\begin{tabular}{|l|c|c|}
\hline \multicolumn{1}{|c|}{ Hypothesis } & Accepted & Not Accepted \\
\hline $\begin{array}{l}\text { H3: Social influence has a positive effect on prospective } \\
\text { retailers' intention to participate in crowdfunding projects }\end{array}$ & $\sqrt{ }$ & \\
\hline $\begin{array}{l}\text { H4: Reliability conditions have a positive effect on prospective } \\
\text { retailers' intention to participate in crowdfunding projects. }\end{array}$ & $\sqrt{ }$ & \\
\hline
\end{tabular}

Besides, the R Square for Cox \& Snell and Negelkerke were 0.571 and 0.764 respectively, which indicates that between $57.1 \%$ and $76.4 \%$ of variation in retailers' intention was explained by the factors fitted in the model Table 5.

Table 5. The Indication of Binary Logistic Regression Model

\begin{tabular}{|c|c|}
\hline Fig. 1. Indication of Model & Fig. 2. Value \\
\hline Fig. 3. $\mathrm{R}$ square & $\begin{array}{c}\text { Fig. 4. Cox \& Snell }=0.571 \text {, Nagelkerke }= \\
0.764\end{array}$ \\
\hline Fig. 5. Omnibus Test of Model Coefficient & Fig. 6. $\quad x^{2}=321.039, d f=4, p=0.000$ \\
\hline Fig. 7. Hosmer and Lemeshow Test & Fig. 8. $\quad x^{2}=8.983, d f=7, p=0.254$ \\
\hline
\end{tabular}

Next, as displayed in Table 6, the results of variables in the equation, there is sufficient proof concluded to confirm that the independent variables could predict the dependent variable. This showed that there is a model fit when the $p$-value for performance expectancy is equal to 0.000 , effort expectancy is equal to 0.471 , social influence is equal to 0.020 , and reliability is equal to 0.006 .

\subsection{Summary of Hypothesis Testing.}

All hypothesis were tested, and it was found that all variables from $\mathrm{H} 1$ to $\mathrm{H} 4$ were accepted. This means that $\mathrm{PE}, \mathrm{EE}, \mathrm{SI}$, and $\mathrm{REL}$ have a positive effect on prospective retailers' intention to participate in crowdfunding projects, as presented in Figure 2.

Table 6. Reliability Result

\begin{tabular}{|c|c|c|c|c|c|}
\hline Step & B & S.E & Wald & df & Sig. \\
\hline PE & 1.783 & 0.263 & 45.816 & 1 & 0.000 \\
\hline EE & -0.321 & 0.446 & 0.519 & 1 & 0.471 \\
\hline $\mathrm{SI}$ & 2.987 & 0.314 & 90.203 & 1 & 0.020 \\
\hline REL & 1.262 & 0.459 & 7.556 & 1 & 0.006 \\
\hline
\end{tabular}

Independent variables that contribute to Low intention to perceived retailer intention is PE, EE, and SI. While Independent variables that contribute to High intention to Prospective retailers' intention is REL $(P<0.001)$. 
Figure 2. Research Hypothesis Result

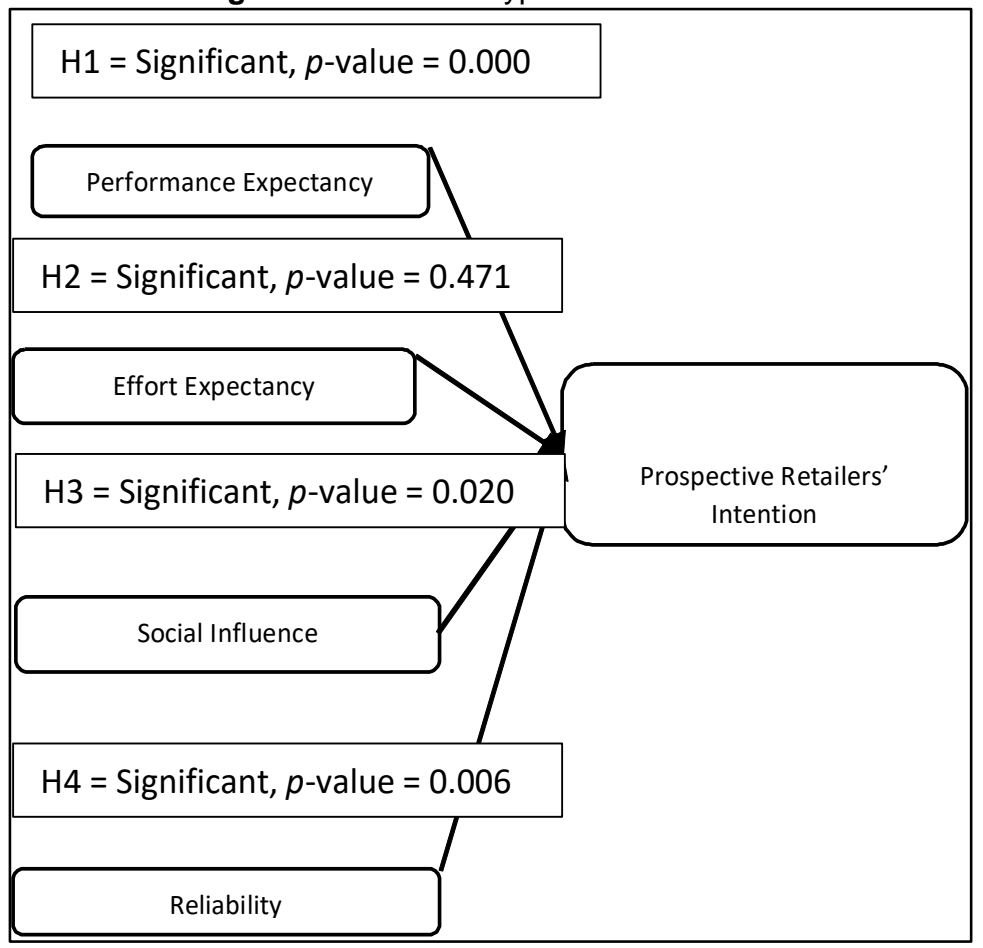

\section{Discussion of Findings.}

As mentioned in Chapter 1 , this study aimed to analyze the factors affecting a prospective investor's intention to contribute to crowdfunding projects based on the UTAUT model with the addition of trustworthiness.

$\mathrm{H}_{1}$ : Performance expectancy has a positive effect on prospective retailers' intention to participate in crowdfunding projects

The result yields that $\mathrm{PE}$ is positively significant to the intention of investors. A similar pattern of results was observed in the studies of (Venkatesh et al., 2003); (Awuah, 2012); and (Zhou et al., 2010). However, comparing the result with the study of (Moon and Hwang, 2018), there is a marked difference in the result of PE. By obtaining adequate information, this study exposed that the intention of the retailer would be influenced by ways to improve and increase the performance of the business in Malaysia. Besides that, crowdfunding will help to make the lives of those associated with retailers' business getting better. Also, crowdfunding is expected to provide new career opportunities for people in developing countries. Hence, to increase the retailers' intention in raising fund from the crowdfunding project, the performance of the crowdfunding initiatives and platform should also increase.

$\mathrm{H}_{2}$ : Effort expectancy has a negative effect on prospective retailers' intention to participate in crowdfunding projects

The finding in this study showed that EE has a negatively significant relationship with investor's intention. The result is in line with the result by previous authors (Venkatesh et al., 2003) and (Hussin, Jaafar and Downe, 2011). Accordingly, it has demonstrated that, in order for the donor to contribute and participate in crowdfunding projects, it is expected from the administrator that the process of investment should be carried out easily, can be learned effortlessly, in addition to straightforwardly processed. This could indicate that, if the process is difficult and not easy to understand, fewer retailers would be willing to collect fund from crowdfunding platform. In addition, the platform should be easily accessible for people with various backgrounds regarding age and level of education. However, EE has the highest impact on the retailer's intention. Although the impact is highest, it could still increase the retailers' intention if the $\mathrm{EE}$ is increased. 
$\mathrm{H}_{3}$ : Social influence has a positive effect on prospective retailers' intention to participate in crowdfunding projects

The findings show that $\mathrm{SI}$ is positively significant to the retailer's intention. The result of this study is similar to that of previous authors (Carter et al., 2011); (Ordanini et al., 2011); and (Kim and Jeon, 2017). Thus, to increase the intention of prospective retailers, greater encouragement should be made with respect to SI. Since SI is related to the word of mouth of the surrounding people, awareness of the importance of crowdfunding should be regularly carried out. Since most people are spending more time browsing the internet through their smartphone, advertising and marketing should be undertaken via crowdfunding platforms such as pitchIN, Mystartr and MDEC. By doing so, more people will become aware to help and invest money for development of retailer's business, and hopefully, they will inform and inspire others. In addition, the organizer and administrator could hire fund manager to encourage more people to invest in the crowdfunding project.

$\mathrm{H}_{4}$ : Reliability has a positive effect on prospective retailers' intention to participate in crowdfunding projects

The result of this study indicates that reliability is positively significant to the retailers' intention. It is similar to previous authors such as (Venkatesh et al., 2003). However, the result is in contrast with the study of (Moon and Hwang, 2018). The intention of the retailer will be influenced by the condition and state of the platform where they are expected to use the crowdfunding platform. Organizers and administrators, therefore, should always be aware and prepared to answer the questions that arise and are posed from the public regarding the usage and the technicalities of the platform used. Moreover, they should accept comments and constructive criticism from the retailers so that they will eventually provide a platform that is convenient for all levels of people. Therefore, retailers' intentions could be encouraging if reliability is increased.

\subsection{Summary.}

At the conclusion of the data collection process, this research was able to gather 379 samples for analysis according to the (Krejcie and Morgan, 1970) sample size calculation. First, the data were analyzed for frequency analysis so that the distribution of gender, age, education, business categories, experience, and willingness to collect amount of fund were known. Second, descriptive analysis was carried out to all variables to determine the data for its mean and standard deviation. In the descriptive analysis, we can know the normality of the data by the results of skewness and kurtosis. Third, the items in the variable underwent EFA to understand whether there were underlying items in the variables. Fourth, the variables were then analyzed for reliability so that the items in the variables could be known for its validity. Fifth, the relationship between the variables was determined by testing its correlation and logistic regression analysis. In this analysis, the researcher was able to determine the impact of the independent variables on the dependent variable. Finally, the results showed that all variables were positively significant to the retailer's intention in raising fund for the crowdfunding project.

\section{Conclusion.}

In order to determine the factors affecting the technology acceptance among retailers of using crowdfunding platform. As mentioned previously, logistic regression analysis helps one to estimate values from data we have about other independent variables on a dependent variable ( $E$. Wagner, 2015, Sharif et al,2018). In this study, the logistic regression analysis explored the factors of each independent variable, namely $\mathrm{PE}, \mathrm{EE}, \mathrm{SI}$, and $\mathrm{REL}$, and the dependent variable, which was the prospective retailer's intention to be involved in crowdfunding projects.

From the results, there is sufficient proof concluded to confirm that the independent variables could predict the dependent variable. This showed that there is a model fit when the $p$-value for PE is equal to 0.000 , EE is equal to $0.471, \mathrm{SI}$ is equal to 0.020 , and REL is equal to 0.006 . Thus, all independents variable were significant except EE which mean more than $(p>0.05)$. 


\section{Acknowledgments}

This paper is part of a research funded by the Ministry of Higher Education Malaysia under the Fundamental Research Grant Scheme (FRGS/1/2020/FPTT-CTED/F00447). The authors also would like thanks to Universiti Teknikal Malaysia Melaka (UTeM) and Centre of Technopreneurship Development (C-TeD) for the support.

\section{References}

1. Ali, R., Ismail, S. and Bakri, M.H. (2015). Proposed Islamic Educational Loan-Backed Securities for Quality Life of University Graduates in Malaysia. Procedia-Social and Behavioral Sciences, 85-92.

2. Ali, R., Ismail, S. and Bakri, M. H. (2013). A Comparative Analysis of Conventional and Shari'ah for Residential Mortgage-backed Securities. Procedia Economics and Finance, 7, 116-125.

3. Al-Lamy, H. A., Bakry, M. H., Raad, W., Al-Shami, S. A., Alaraji, Z. J., Alsa-Lihi, M. W., \& Al-Tameemi, H. M. (2018). Information technology infrastructure and small medium enterprises' in Iraq. Opcion, 34(86), 1711-1724.

4. Ajzen, I. and Fishbein, M., (1977). Attitude-Behavior Relations: A Theoretical Analysis and Review of Empirical Research", Psychological Bulletin. Tittle \& Hill.

5. Asian Institute of Finance. (2014). Asian Link: Industry Outlook 2014. Available at: www.rekacetak.com (Accessed: 6 October 2020).

6. Asian Institute of Finance. (2017). Crowdfunding Malaysia's Sharing Economy: Alternative Financing For Micro, Small, and Medium Enterprises. Asian Institute of Finance, Kuala Lumpur. Available at: https://fsi-v2.fidonethost.com/wp-content/uploads/2019/03/Research-Report-CrowdfundingMalaysias-Sharing-Economy.pdf (Accessed: 6 October 2020).

7. Awuah, L. J. (2012). An Empirical Analysis of Citizens' Acceptance Decisions of ElectronicGovernment Services: A Modification of the Unified Theory of Acceptance and Use of Technology (UTAUT) Model to Include Trust, pp. 1036-1037.

8. Bakri, M.H, Ali, R. and Ismail, S. (2016). Developing Primary Market Spread and Measuring Financial Performance of Staff Housing Government Loans. Proceedings of the 1st AAGBS International Conference on Business Management, 501-511.

9. Bakri, M.H, Dabas.N, Ismail, S. and Baharom, A.H. (2017). Islamic Student Financing Back Securitization in Malaysia. Advanced Science Letters, 23(9), 8090- 8093.

10. Bakri, M.H., Sufian, F., Baharom, A.H. and Ismail, S. (2018). Determinant of Securitization Spread in Malaysia, International Journal of Business and Society 19 (3), 904-917.

11. Bakri, M.H., Ali, R., Ismail, S. (2015). The study of residential mortgage backed securities during subprime mortgage: Malaysian experience Advanced Science Letters, 21(5), pp 1468-1472.

12. Burkett, E., (2011). A Crowdfunding Exemption? Online Investment Crowdfunding and U.S. Securities Regulation. Available at: http://www.sec.gov/news/press/schapiro- (Accessed: 5 October 2020).

13. Burtch, G., Ghose, A. and Wattal, S., (2012). An Empirical Examination of the Antecedents and Consequences of Contribution Patterns in Crowd-Funded Markets, Available at: http://ssrn.com/abstract=1928168http://ssrn.com/abstract=1928168http://ssrn.com/abstract=19 28168 (Accessed: 5 October 2020).

14. Carter, L. et al. (2011). The Role of Security and Trust in The Adoption of Online Tax Filing. Iss Iss Online Information Review, 5(3), pp. 303-318.

15. Davis, F. D. (1989). Perceived Usefulness, Perceived Ease of Use, and User Acceptance of Information Technology, Delle vicende dell'agricoltura in Italia; studio e note di C. Bertagnolli, 13(3), pp. 319-340. 
16. Dipietro, W. and Sawhney, B. (1977). Business Failures, Managerial Competence, and Macroeconomic Variables. American Journal of Small Business, 2(2), pp. 4-15.

17. E. Wagner, W. (2015). Using IBM SPSS Statistics for Research Methods and Social Science Statistics, Acta Universitatis Agriculturae et Silviculturae Mendelianae Brunensis.

18. Faique, F.A, Ismail, S., Taib, N.M., Bakri, M.H., Yazid, Z.A, Daud, S. and Idris, N.H. (2017). Testing the financial attitude as a mediator for the relationship between financial self-efficacy with financial behavior. Journal of Computational and Theoretical Nanoscience, 23(8), pp. 8009-8012.

19. Fredland, J. E. and Morris, C. E. (1976). A Cross Section Analysis of Small Business Failure, American Journal of Small Business, 1(1), pp. 7-18.

20. Hu, E., (2017). SME Challenges \& Solutions: A Practical Guide For SMEs To Elevate Their Businesses To The Next Level.

21. Huang, C.-Y. and Kao, Y.-S., (2015). UTAUT2 Based Predictions of Factors Influencing the Technology Acceptance of Phablets by DNP.

22. Hussin, N. H., Jaafar, J. and Downe, A. G. (2011). Assessing educators' acceptance of Virtual Reality (VR) in the classroom using the Unified Theory of Acceptance and Use of Technology (UTAUT), Lecture Notes in Computer Science (including subseries Lecture Notes in Artificial Intelligence and Lecture Notes in Bioinformatics), 7066 LNCS (PART 1), pp. 216-225.

23. Ismail, S., Faique, F.A., Bakri, M.H., Zain, Z.M., Idris, N.H., Yazid, Z.A. (2017). The Role of Financial Self-Efficacy Scale in Predicting Financial Behavior. Advanced Science Letters, 23(5): 4635-9

24. Kim, S. and Jeon, I. (2017). Influencing Factors on the Acceptance for Crowdfunding-Focusing on Unified Theory of Acceptance and Use of Technology, 27(2), pp. 150-156.

25. Krejcie, R. V and Morgan, D. (1970). Determine Sample Size for Research Activities, The NEA Research Bulletin, 30, pp. 607-610.

26. Mohd Noor, N.H.H, Bakri, M.H, Wan Yusof, W.Y.R, Mohd Noor, N.R.A, Zainal, N. (2020). The Impact of the Bank Regulation and Supervision on the Efficiency of Islamic Banks, Journal of Asian Finance, Economics and Business, 7(11), 747-757.

27. Mohd Noor, N. H. H., Bakri, M. H., Yusof, W. Y. R. W., Noor, N. R. A. M., \& Abdullah, H. (2020). The determinants of bank regulations and supervision on the efficiency of Islamic banks in MENA Regions. Journal of Asian Finance, Economics and Business, 7(12), 245-254.

28. Moon, Y. and Hwang, J. (2018). Crowdfunding as an alternative means for funding sustainable appropriate technology: Acceptance determinants of backers, Sustainability (Switzerland). MDPI AG, 10(5), p. 1456.

29. Ordanini, A. et al. (2011). Crowd-funding: Transforming customers into investors through innovative service platforms, Journal of Service Management, 22(4), pp. 443-470.

30. Pallant, J. (2011). SPSS Survival Manual. Edited by O. U. Press. McGraw-Hill Education.

31. Peterson, R. A., Kozmetsky, G. and Ridgway, N. M., (1983). Perceived Causes of Small Business Failures: A Research Note, American Journal of Small Business, 8(1), pp. 15-19.

32. Rahim, N.F., Bakri, M.H. and Yahaya, S.N. (2019), "Fintech and Shariah principles in smart contracts", in Rafay A. (Ed.), FinTech as a Disruptive Technology for Financial Institutions, IGI Global, Hershey, PA, pp. 207-220.

33. Rahman A, Hayati N, Sahiq M, Nadiah A, Ismail S, Bakri MH, et al. (2016). Antecedents of a successful business venture for young entrepreneurs. Advanced Science Letters, 22(12): 4485-8.

34. Securities Commission Malaysia, (2019). New ECF, P2P Financing Operators and Property Crowdfunding Framework Announced at SC Fintech Roundtable - Media Releases and Announcements | Securities Commission Malaysia, Available at: 
https://www.sc.com.my/resources/media-releases-and-announcements/new-ecf-p2p-financingoperators-and-property-crowdfunding-framework-announced-at-sc-fintech-roundtable (Accessed: 7 October 2020).

35. Sharif, S. M., Nizam, N. Z., Rashid, N. A., Masrom, N. R., \& Bakri, M. H. (2018). Role of values and competencies in university intellectual property commercialization: A critical review. The Turkish Online Journal of Design, Art and Communication, 887-904.

36. Shin, D. and Hwang, Y. (2017). Integrated acceptance and sustainability evaluation of Internet of Medical Things: A dual-level analysis, Internet Research. Emerald Group Publishing Ltd., 27(5), pp. 1227-1254.

37. Straub, E. T. (2009). Understanding technology adoption: Theory and future directions for informal learning, Review of Educational Research, 79(2), pp. 625-649.

38. Terpstra, D. E. and Olson, P. D. (1993). Entrepreneurial Start-up and Growth: A Classification of Problems, Entrepreneurship Theory and Practice. SAGE Publications, 17(3), pp. 5-20.

39. Venkatesh, V. et al. (2003). User Acceptance of Information Technology: Toward a Unified View, Inorganic Chemistry Communications, 67(3), pp. 95-98.

40. Voorbraak, K. (2011). Crowdfunding for financing new ventures: consequences of the financial model on operational decisions, Alexandria. Tue. NI, (August).

41. Zhou, T., Lu, Y. and Wang, B. (2010). Integrating TTF and UTAUT to explain mobile banking user adoption, Computers in Human Behavior. Elsevier Ltd, 26(4), pp. 760-767. 